\title{
INFORMAÇÃO, GLOBALIZAÇÃO E EDUCAÇÃO: desafios de uma nova era
}

\author{
Ana Maria Pereira
}

\section{Resumo}

O presente artigo não possui a pretensão de ser um texto aprofundado sobre as questões expostas, mas suscitar questionamentos e despertar nosso interesse para problemas tão gritantes sobre a interação entre educação e informação e o uso das tecnologias por esses seguimentos dentro de um contexto globalizado. Aponta a globalização como instrumento do desenvolvimento do processo educacional gerador do conhecimento e da transmissão da informação, interferindo no perfil de nossos educadores e educandos, num contínuo e complexo contexto global, como um caminho sem volta para a educação.

\section{Palavras chave}

Educação; Informação; Globalização; Tecnologia da Informação

informacionais.

Se pensarmos na informação como

Tratar de assuntos tão desafiantes e complexos torna-se ainda mais difícil, quando temos consciência de não dominá-los.

Podemos analisar a informação como um processo cíclico do conhecimento, visando sempre alcançar o maior número de pessoas por meio das tecnologias veículo do conhecimento, nos deparamos com um outro conceito mais abrangente e mais profundo que o simples fato de informar, verificamos a informação como instrumento educacional de formação do conhecimento humano.

Estamos em uma "era" de mudanças, 
onde o mundo transforma-se a cada segundo.

Segundo García (1995, p.148),

"assistimos ao nascimento de um novo paradigma, um novo modelo, de características similares de importância equiparável ao da aparição da imprensa, de uma revolução que em suma, afetará os hábitos de comportamento e, sobretudo, os modos de perceber a realidade, como ocorre com toda a modificação ou inovação operada nos sistemas de representação e transmissão do conhecimento".

Entramos na corrida contra o tempo. Podemos acompanhar a história através dos livros didáticos e a complexa evolução do mundo globalizado. A explosão da globalização deu-se no início do século XX, quando as tecnologias avançaram em desenvolvimento, alcançando até mesmo os países de terceiro mundo mais marginalizados da história da humanidade.

As tecnologias estão ocupando espaços que antes eram dos homens, atualmente os mesmos são substituídos pelas máquinas. A informação passa por processo rápido e constante de mudanças e é disponibilizada com a velocidade da luz. E a educação, qual seu significado nesse mercado abrangente e concorrente?

Segundo Ianni (1996, p. 24), “a globalização não é um fato acabado, mas um processo em marcha".

Atualmente, quem não faz parte desse processo, está fora do contexto social e mundial. O "boom" da economia, em que podemos citar as recentes quedas das bolsas de valores nos países asiáticos são capazes de abalar a economia mundial e até mesmo trazer sérias conseqüências para países como o Brasil que está tão distante.

Segundo lanni (1995, p.14), "esse é um processo simultaneamente civilizatório, já que desafia, rompe, subordina, mutila, destrói ou recria outras formas sociais de vida e trabalho, compreendendo modos de ser, pensar, agir, sentir e imaginar."

Só nos resta questionar até que ponto é positivo todo esse domínio. Em que pode toda essa tecnologia contribuir para a Educação? Como trabalhar a informação junto às tecnologias dentro de um contexto globalizado de forma a torná-la um instrumento de educação mundial?

A globalização da economia, da cultura, da educação, da informação, está indo ao encontro de que interesse, ou seja, interessa a quem?

A preocupação maior gira em torno da educação e como a informação pode contribuir para o desenvolvimento do conhecimento.

Segundo Reich (apud IANNI, 1996), "na nova economia global, a inteligência também não obedece mais a fronteiras ou nacionalidades".

A educação deve caminhar paralelamente ao desenvolvimento das tecnologias utilizando-se das mesmas para aplicar de maneira mais rápida e precisa o conhecimento científico e aplicado, buscando solucionar os problemas de aprendizagem humana.

As tecnologias agem diretamente no perfil de nossos educadores e educandos, globalizando o conhecimento e a informação que deixam de ser individuais e passam a ser coletivos. 
É importante observar que as necessidades causadas pela globalização pertencem a um contexto amplo e intenso que nos insere no contexto global de forma sutil e incisiva.

Segundo Batista Jr. (1996), "A globalização é tão velha como Matusalém”.

Ao comprarmos uma coca-cola, estamos fazendo parte do contexto global, bem como ao utilizarmos as telecomunicações, videocassetes, computador, a Internet, e até mesmo o nosso velho e conhecido quadro-negro e o giz, tecnologias ultrapassadas, mas que no entanto, inserido em seu contexto, fazem parte de uma história globalizada como recurso educacional.

O profissional da informação deve integrar-se com outros profissionais num trabalho multidisciplinar, pois essa interação fará mudanças extraordinárias. A educação é uma área em que existe constantes mudanças e multidisciplinariamente é também a área que nos dá exemplos de total interação.

É necessário que essa interação de certa forma esteja seguindo padrões ditados pelo mundo todo, ou seja, projeto do mundo globalizado.

Para Azevedo (1932, p. 60), “um educador pode bem ser um filósofo e deve ter a sua filosofia de educação; mas, trabalhando cientificamente nesse terreno, ele deve estar tão interessado na determinação dos fins de educação, quanto também dos meios de realizá-los".

A consciência do verdadeiro papel do educador deve estar de acordo com as necessidades da sociedade em que ele atua, isso impõe a concentração da consciência educacional perante a sociedade, para que todo o esforço de se criar uma educação fortalecida pela interação educador/educando possa encontrar o respaldo necessário na utilização das tecnologias educacionais com uma maior amplitude, multiplicando-Ihe a eficácia e sua extensão perante a sociedade local e internacional.

Para dominar toda essa tecnologia que está disponível, é preciso estar capacitado para isso e ter acesso aos instrumentos tecnológicos. Faz-se necessário que os educadores estejam preparados para utilizar e ensinar o uso e, o mais importante, a finalidade do uso das tecnologias em sala de aula. No mundo globalizado a educação torna-se mercado. Não entende-se a educação como simples meio de adquirir conhecimento, mas sim, como forma de comercializar o conhecimento. Esse é um dos fatores que nos traz a globalização, transforma a educação em objeto de consumo. Permanecem no mercado os educadores que estiverem dotados de todos os conhecimentos, inclusive o de domínio da tecnologia e que estejam abertos a aprender sempre. Estamos abertos à concorrência.

Não é preciso ir muito longe. Atualmente vemos uma corrida muito grande das escolas em busca de melhores equipamentos, de professores melhor formados (tecnicamente ${ }^{1}$ ) e o governo deixando de ser o responsável maior pela educação, dividindo sua responsabilidade com a iniciativa privada e com as comunidades locais.

\section{O que acarreta tais mudanças? A}

\footnotetext{
1 Quando nos referimos ao termo "tecnicamente", estamos fazendo alusão a um outro processo globalizado, em que as universidades, em sua maioria, não estão interessadas em formar profissionais pensantes, mas técnicos, ou seja, meros cumpridores do dever em sala de aula.
} 
globalização da educação em virtude do uso de tecnologias. Ou se está dentro do mercado, ou se está fora dele. Porém, é imprescindível questionar: quem está direcionando esse caminho? Fazemos parte de uma sociedade global, onde poucos pensam e decidem por muitos. Servimos sempre aos interesses dos "mais fortes".

A tecnologia trouxe-nos para um mundo sem fronteiras, onde ninguém é dono de ninguém. Perdemos nossa individualidade, nossa privacidade. É assustador notar que uma técnica desenvolvida nos momentos das grandes guerras, para controlar as pessoas e traçar novas estratégias de guerra, continui hoje com os mesmos objetivos, e assuma um caráter social de desenvolvimento cultural e educacional, globalizando a informação e o conhecimento. As idéias que antes pertenciam basicamente ao seu criador e às pessoas de seu interesse, hoje pertencem ao mundo. A Internet cuidou de "mundializar" todo e qualquer tipo de informação e/ou conhecimento.

Nesse processo de ensino/aprendizagem, produção/comércio, a construção do conhecimento por meio de pedagogias e tecnologias educacionais estão utilizandose de mecanismos didáticos e tecnológicos independentes de ser acadêmicos ou não, onde é possível entender essa interação entre o indivíduo e o global, tornando-os sujeitos no processo da produção do conhecimento em um câmbio mútuo de informações e aprendizagens.

É necessário esclarecer que as tecnologias são um meio e não um fim, quando se pensa em sua utilização enquanto disseminadora da informação e como instrumento educacional.

É um desafio pensar a educação como instrumento maior dentro desse mundo globalizado. Onde a globalização irá nos le- var? Essa é a pergunta da maioria dos estudiosos atualmente. Nesse final de século, em que para o mundo globalizado a informação tem peso de ouro e a educação é o único meio de continuar competindo no mercado e fazendo com que o ser humano ainda se sinta um "ser humano" - visto que as máquinas estão ocupando cada vez mais espaços -, é instigante perguntar o que fazer com nossa "inteligência", como trabalhar o individual sem prejudicar o coletivo, visto que como já citamos acima não somos donos nem de nosso próprios pensamentos.

Há ainda um questionamento a ser feito perante tantas dificuldades e desafios: Como utilizar-se das tecnologias, globalização da educação e de nossos intelectuais, trabalhando a informação dentro desse contexto globalizado, sem perder nossa identidade cultural, social, histórica e educacional?

Segundo Vigevani (1996, p.1-2),

"sabemos que as descobertas realizadas pela humanidade ao longo dos séculos estão entrelaçadas com as relações de produção existentes, com as necessidades sociais ou, no plano abstrato, com as preocupações culturais, com a necessidade de respostas a temas colocados em cada época. Neste sentido, cabe reconhecer que as tecnologias da informação, derivadas da revolução na microeletrônica em curso na segunda metade do século $X X$, corresponderam às novas necessidades do desenvolvimento capitalista, a uma fase nova, com características próprias, da internacionalização da produção, que se convencionou chamar de globalização. Em outras pala- 
vras, as novas tecnologias da informação constituem o pressuposto técnico das formas alcançadas pelo sistema produtivo: cada vez mais menos dependente de mercados locais e cada vez mais mundializados no que tange a produção e ao consumo".

O autor expõe "conceituar a informação como parte constitutiva da produção de bens, de serviços e de cultura vincula-se diretamente ao tema da globalização, a qual implica uma forma de organização da produção". (VIGEVANI, 1996, p. 14).

Penso que esse conceito aplica-se também à Educação que constituída como parte da produção de bens, de serviços e de cultura, vincula-se diretamente ao tema da globalização.

Educação e informação não podem ser entendidas distintamente dentro de nosso atual contexto globalizado, somente podemos entendê-lo no sentido de aprimorar o homem na busca pelo conhecimento e seu desenvolvimento holístico.

É preciso desenvolver a capacidade de inovar, de produzir novos conhecimentos e buscar soluções científicas e tecnológicas que possam adquirir as nossas necessidades sociais, e isso exige muito do nosso sistema educacional, que vêm sendo pressionado por responder às mudanças pela educação global.

Atualmente, a sociedade e de certa forma as tecnologias educacionais nos levam a pensar de forma ampla - global - e agir localmente. É dentro do contexto em que estamos inseridos que nos identificamos, que aprendemos, que formamos nosso ciclo de vida, em que desde um simples sorriso de alguém amigo nos faz sentir "hu- manos", e podemos transmitir isso de geração em geração. dade?

Será que passa por aí, nossa identi-

É preciso olhar dentro de nossa pequenez para que possamos perceber a importância do processo local e o porque estamos sempre sendo levados a pensar de forma ampla.

Não é preciso ser um intelectual para entender o que acontece no mundo. Cai a bolsa de valores, vai pesar no bolso de quem? Estoura a Guerra no Golfo, refletiu na economia e na política de que países? Foi lançado um novo satélite, as informações são lançadas instantaneamente a todo e qualquer lugar do mundo.

A globalização torna-se fruto do crescente desenvolvimento da civilização e do avanço das tecnologias. Porém é necessário analisar que é também uma "faca de dois gumes". É tão conflitante entre si, que fica difícil distinguir entre o que é bom e o que é ruim em nosso atual contexto.

Para Lafee (1993, p.68), ao sintetizar o tema globalização, o autor

"não elimina os temas da hegemonia e da desigualdade, mas os torna mais complexos. As formas de exercício hegemônico variam; em muitas circunstâncias, o disfarce é a defesa da globalização, o que pode tornar necessário, como mecanismo de resistência, a defesa das identidades e das especificidades nacionais. $O$ contraste entre o discurso e a prática liberais do mundo desenvolvido é uma lição permanente de cautela diante de soluções doutrinárias que se 
apresentam como prontas e definitivas".

É necessário olhar a educação dentro desse contexto globalizado de forma crítica e entendê-la como fonte geradora do conhecimento e transmissão da informação. A informação, como precursora da educação, leva o ser humano a absorver e gerar conhecimento. Se pensarmos em informação, dentro do contexto amplo, podemos perceber que a comunicação está inserida na informação e ambas estão de certa forma contribuindo para o desenvolvimento educacional.

Concordamos com lanni (1996, p.35), que nos esclarece de maneira sensata esses questionamentos e nos leva a novos caminhos e formas de pensamentos quando diz que

"...os conceitos envelhecem, ficam descolados do real, já que o real continua a mover-se transformar-se. Em certos momentos, ele parece repetir-se de modo enfadonho, mas em outros revela-se diferente, novo, fascinante, insólito, surpreendente. Sob vários aspectos, pode se dizer que aqui começa a história novamente"
ALBA, Luís. El profesional de información y los cambios globales: temas para un debate. p.45-57. In: II SIMPÓSIO INTERNACIONAL "PROF. DR. PAULO TARCÍSIO MAYRINK" e IV ENCONTRO DE BIBLIOTECONOMIA DO CENTRO OESTE PAULISTA, 04 a 06 de setembro de 1996. Anais... Marília: Faculdade de Filosofia e Ciências da UNESP, 1997.

AZEVEDO, Fernando. A reconstrução educacional no Brasil: manifesto dos pioneiros da educação nova. In: A educação entre mundos: problemas, perspectivas e orientações. São Paulo: Melhoramentos, 1958. p.59-81. (Obras Completas V. XVI).

BATISTA JÚNIOR, Paulo N. O mito da globalização. Folha de São Paulo, 07 de outubro de 1996.

BOSI, Alfredo. Dialética da colonização. São Paulo: Companhia das Letras, 1992. 412p.

DOWBOR, Ladislau. Da globalização ao poder local: a nova hierarquia dos espaços. In: FREITAS, Ramos C. de. A reinvenção do futuro. São Paulo: Cortez, 1996. p.5575.

GARCÍA, José Antonio Cordón. De D’Alembert al CD-ROM: las enciclopedias electronicas o la aparicion de un nuevo paradigma. Revista Española de Documentación Científica, v.18, n.4, p.418425, Octubre-Deciembre, 1995.

IANNI, Octavio. A sociedade global. 3.ed. Rio de Janeiro: Civilização Brasileira, 1995. $194 p$.

A era do globalismo. 2.ed. Rio de Janeiro: Civilização Brasileira, 1996. $342 p$.

KAWAMURA, Lili. Novas tecnologias e educação. São Paulo: Ática, 1990. 80p. (Série princípios, 184). 
LAFER, Celso; FONSECA JR., Gelson. Questões para a diplomacia no contexto internacional das polaridades indefinidas (notas analíticas e algumas sugestões). In: FONSECA JR., Gelson; CASTRO, Sérgio H. Nabuco, (Org.). Temas de política externa brasileira II. Brasília: IPRI, 1993.

MARRAMAO, Giocomo. Paradoxos do universalismo: indivíduo e comunidade na idade global. In: LOUREIRO, Maria Isabel. Liberalismo e socialismo: velhos e novos paradigmas. São Paulo: UNESP, 1995. p.131-147. (Seminários e debates).

NASCIMENTO NETO, Antenor. A roda global. Veja, 3 de abril de 1996.

NISKIER, Arnaldo. Tecnologia educacional: uma visão política. Petrópolis: Vozes, 1993. $182 p$.

VIGEVANI, Tullo. Globalização e informação: as questões não resolvidas. p.61-70. In: II SIMPÓSIO INTERNACIONAL "PROF. DR. PAULO TARCÍSIO MAYRINK" e IV ENCONTRO DE BIBLIOTECONOMIA DO CENTRO OESTE PAULISTA, 04 a 06 de setembro de 1996. Anais... Marília: Faculdade de Filosofia e Ciências da UNESP, 1997.

\section{Ana Maria Pereira}

Bacharel em Biblioteconomia e aluna do programa de Pós-Graduação - Mestrado em Educação - UNESP - Marília/SP.

\section{Title}

Information, globalization, and education: challenges of a new era

\begin{abstract}
The present article does not intend to dig deep into the issues, but aims at eliciting questionings and awakening our interest regarding acute problems about the interaction between education and information as well as the use of technologies by these segments within a globalized context. It points out globalization as an instrument for the development of the educational process which generates knowledge and information transmission, interfering in the profile of educators and learners in a continuous and complex global context.
\end{abstract}

\section{Keywords}

Education; Information; Globalization.

\section{Titulo}

Información, globalización y educación: desafios de una nueva era

\section{Resumen}

El presente artículo no tiene la pretensión de ser un texto profundo sobre las cuestiones expues- 
tas, sino de suscitar cuestionamentos y despertar nuestro interés para problemas tan gritantes sobre la interacción entre educación e información y el uso de las tecnologías por esos segmentos dentro de un contexto globalizado. Señala la globalización como instrumento del desarrollo del proceso educacional generador del conocimiento y de la transmisión de la información, interfiriendo en el perfil de nuestros educadores y educandos, en un continuo y complexo contexto global, como un camino sin vuelta para la educación.

\section{Palabras-Clave}

Educación; Información, Globalización; Tecnología de la Información

Artigo recebido em: 30/04/98 